\title{
Optimization of the Drive System Choice for a Class of Drilling Machines
}

\author{
Marin M. Zhilevski and Mikho R. Mikhov
}

\begin{abstract}
In this paper are analyzed and formulated the basic requirements for the drive system of a class of modernized drilling machines. On this basis, a methodology for optimal choice of the feed and spindle drives is offered. The respective algorithm takes into account the specific features of the technological processes, the processed materials, the tools used and their wear, as well as the mechanical gear types. Examples with DC and AC motor drives for the coordinate axes and the spindle are presented, illustrating the practical application of the offered methodology. The research carried out and the results obtained can be used in the development of drive systems for the studied class of machine tools.
\end{abstract}

Index Terms-Drilling machines, Drive system choice, Feed drives, Spindle drives, Methodology for drives selection.

\section{INTRODUCTION}

The technical potential of modern machine tools with digital program control depends on both their control systems and the functionality of the respective drive systems. The role of the drives in machine tools increases constantly and currently they affect even the structures of the driven mechanisms.

Drilling machines are used for processing of various workpieces with holes, threads and other types of operations [1]-[3]. Usually they are combined with milling machines, consisting of three or more feed axes, spindle and auxiliary drives [4], [5]. For this reason, their positional accuracy and speed significantly influence on the quality and productivity of machine tools [6].

With respect to modernization of a type of drilling machines, a number of electric drives have been analyzed, allowing choice of the appropriate drive system meeting the performance requirements.

Compared to other types of drives, the electric ones have a number of advantages and meet high demands such as: wide range of speed regulation; high precision of the position control; good dynamics; reliability; economical operation; easy maintenance; good communication abilities, etc. [7], [8].

In this paper, the main requirements for the respective drives of a type of drilling machines with digital program control are formulated and on this basis, a methodology for selection of an appropriate electric drive system is developed. In choosing suitable feed and spindle drives, a number of essential factors were taken into account,

Published on September 27, 2018.

M. M. Zhilevski, Faculty of Automatics, Technical University of Sofia, Bulgaria, (e-mail: mzhilevski@tu-sofia.bg).

M. R. Mikhov, Faculty of Automatics, Technical University of Sofia, Bulgaria (e-mail: mikhov@ tu-sofia.bg). namely: the technological process features, the processed materials, the tools used and the mechanical gears. Examples for selection of feed and spindle drives with DC and $\mathrm{AC}$ motors are shown, illustrating the practical application of the offered methodology. Some experimental results are presented and discussed.

\section{MAIN REQUIREMENTS FOR THE DRIVE SYSTEM}

The drive system for drilling machines consists of some subsystems, including feed drives, spindle drive and auxiliary drives.

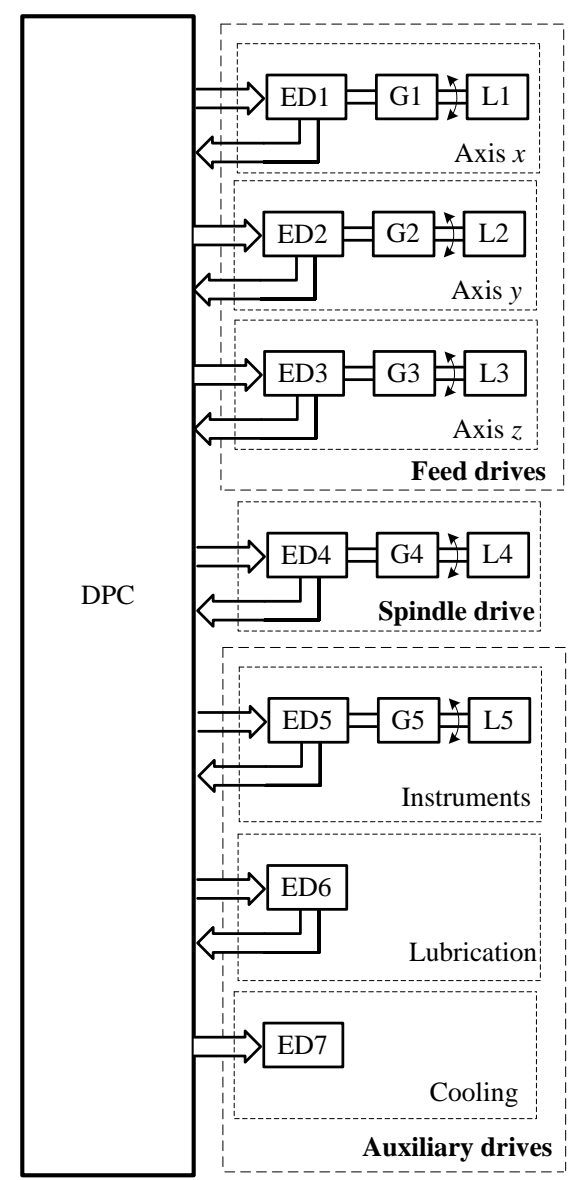

Fig. 1. Block diagram of the drive system for drilling machines.

The simplified block diagram of the drive system for these machines is shown in Fig. 1, where the following notations are used: DPC - digital program control device; ED1 - ED7 - electric drives; G1 - G5 - mechanical gears; L1 - L5 - loads.

Each of the presented drive subsystems has specific features and requirements that need to be taken into account in the process of design, study and application.

The feed drives of the $x, y$ and $z$ coordinate axes are used 
for positioning of the tool and the workpiece at the desired locations and they participate in the machining process. The main requirements for them can be formulated as follows:

- smooth speed regulation in a wide range;

- good dynamics;

- high position accuracy;

- formation of the necessary position cycles;

- providing the required torque;

- reversible speed and torque control;

- compensation of the disturbances;

- easy maintenance;

- reliability;

- economy.

The spindle drive is involved in the machining process and it should meet the following requirements:

- dual-zone speed regulation (by constant torque and constant power respectively);

- high maximum speed;

- sufficient torque;

- oriented braking with high accuracy;

- reversible speed control.

The main requirements for the auxiliary drives can be formulated as follows:

- instrument subsystem providing choice of the desired tool with high precision;

- dosing lubrication of the machine coordinate axes;

- cooling subsystem with possibility of automatic and manual braking and starting from the control panel in order to reduce energy consumption.

The choice of appropriate electric drives for the studied class of machines includes selection of motors, power converters, controllers, sensors and mechanical gears. This problem is extremely important in terms of performance, techno-economic parameters, reliability, etc.

\section{AlgORITHM FOR DRIVE SYSTEM SELECTION}

A unified approach for the designing process of feed and spindle drives is applied, including the following basic stages:

- development of a methodology for optimal choice of these drives;

- calculations, according to the respective procedures of the methodology;

- technical and economic analysis of the possible variants of electric drives;

- modeling and computer simulation of the relevant dynamic and static modes of operation;

- experimental study to evaluate the actual performance of the drive system.

When choosing an electric drive, it is essential to precisely define the heaviest processing mode of operation for the machine to optimize the power and the price.

Fig. 2 shows the simplified block diagram of the developed algorithm for selection of feed and spindle drives.

The used notations are as follows: $D_{g d}$ - nominal diameter of the mechanical gear made by a ball screw; $D_{c d \text { max }}-$ maximum drill diameter that can be used by the machine; $H_{B}-$ Brinell hardness of the processed material; $V_{d \max }-$ maximum speed of the driven mechanism; $V_{c d}-$ cutting speed; $\omega_{d}$ - spindle speed; $V_{f d}$ - feed speed; $f_{r d}$ - feed per radian; $f_{z d}$ - feed per tooth; $\mathrm{z}$ - number of tool teeth; $K_{c f z d}$ - specific cutting force, when feeding the tool tooth; $\eta_{d}$ - efficiency of the drilling machine; $P_{c d \text { max }}-$ maximum power needed to perform cutting, distributed between both feed drive and spindle drive without taking into account the tool wear; $P_{c d w}$ - power needed to perform cutting, distributed between both feed drive and spindle drive with taking into account the tool wear; $P_{s p d}-$ power required only for the spindle drive; $P_{f d}$ - power required only for the feed drive; $h_{d_{i}}$ - nominal steps of the ball screw; $\omega_{f d_{i}}$ - speeds of the motor for different nominal steps of the ball screw; $M_{f d_{i}}$ - motor torques for different nominal steps of the ball screw; $i=1 \div n$, where $n$ is the variant number.

In the proposed methodology, a ball screw couple was used as a mechanical gear with a specified screw diameter. The design and calculation of ball screws is described in ISO/DIN standards [9], [10].

The input data are as follows: definition of the heaviest cutting regime, $D_{c d \text { max }}, D_{g d}, \eta_{d}$ and $V_{d \text { max }}$.

The tabular data used in this methodology are taken from [11] and [12].

The spindle speed is determined by the expression [11]:

$$
\omega_{d}=\frac{V_{c d} \times 2}{D_{c d \max }}
$$

The drilling feed speed is calculated using the following equation [11]:

$$
V_{f d}=f_{r d} \times \omega_{d}
$$

The maximum power needed to perform cutting, distributed between both feed drive and spindle drive without taking into account the tool wear, is calculated by the next expression [11]:

$$
P_{c d \max }=\frac{D_{c d \text { max }} \times f_{r d} \times V_{c d} \times K_{c f z d} \times \pi \times 10^{6}}{2 \eta_{d}} .
$$

The maximum power needed to perform cutting, distributed between both feed electric drive and spindle electric drive with taking into account the tool wear, is determined by the equation [11]:

$$
P_{c d w}=(1.1 \div 1.3) \times P_{c d \max } \text {. }
$$

The power required for the spindle drive is calculated by the expression [13]:

$$
P_{s p d}=(95 \div 99) \% \times P_{c d w} \text {. }
$$




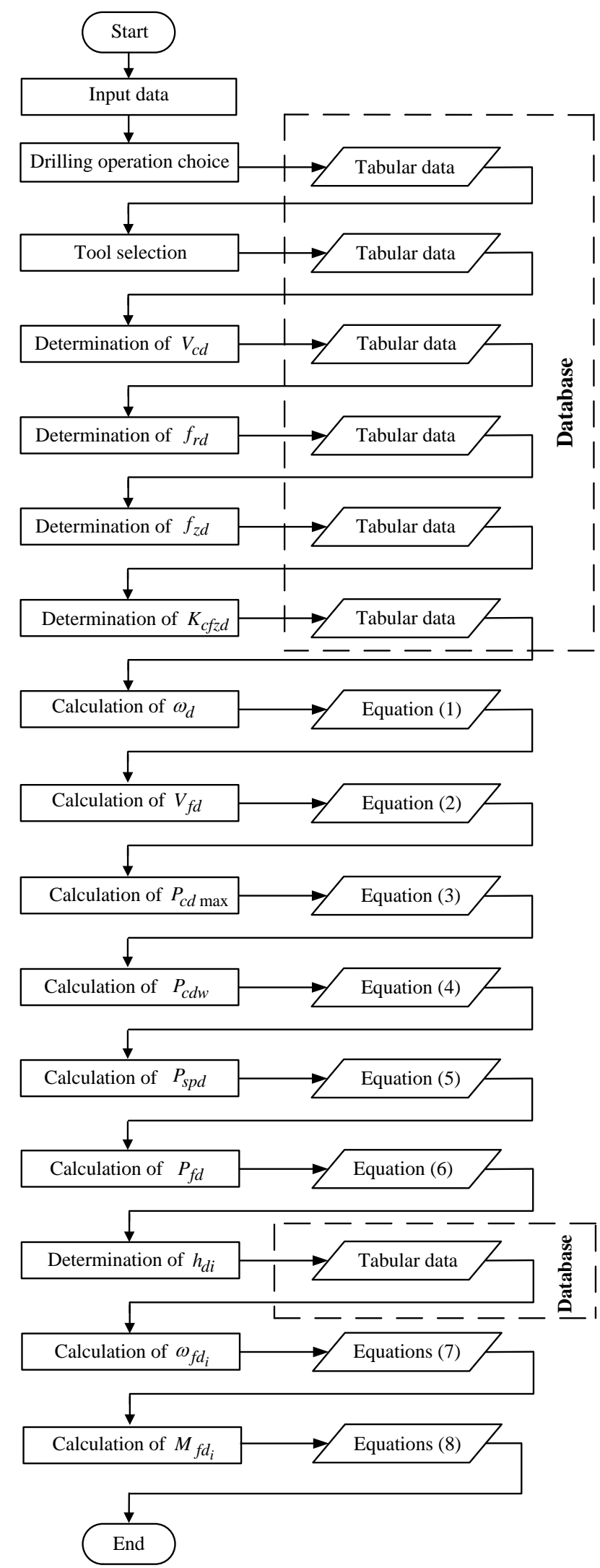

Fig. 2. Block diagram of the algorithm for choice of electric drives.

The power required only for the feed drive is determined as follows [13]:

$$
P_{f d}=(1 \div 5) \% \times P_{c d w}
$$

The motor speeds for different nominal steps of the ball screw are calculated by the following expressions [14]:

$$
\left.\begin{array}{l}
\omega_{f d_{1}}=\frac{V_{d \max } \times 2 \times \pi}{h_{d 1}} \\
\vdots \\
\omega_{f d_{n}}=\frac{V_{d \max } \times 2 \times \pi}{h_{d n}}
\end{array}\right\} .
$$

The torques of the motor for different nominal steps of the ball screw are determined by the following equations:

$$
\left.\begin{array}{l}
M_{f d_{1}}=\frac{P_{f d}}{\omega_{f d_{1}}} \\
\vdots \\
M_{f d_{n}}=\frac{P_{f d}}{\omega_{f d_{n}}}
\end{array}\right\} .
$$

The offered methodology for drives selection takes into account the specific features of the technological processes, the processed materials, the tools used and their wear, as well as the mechanical gear types. It gives opportunity for choice of motors, power converters, mechanical gears and sensors.

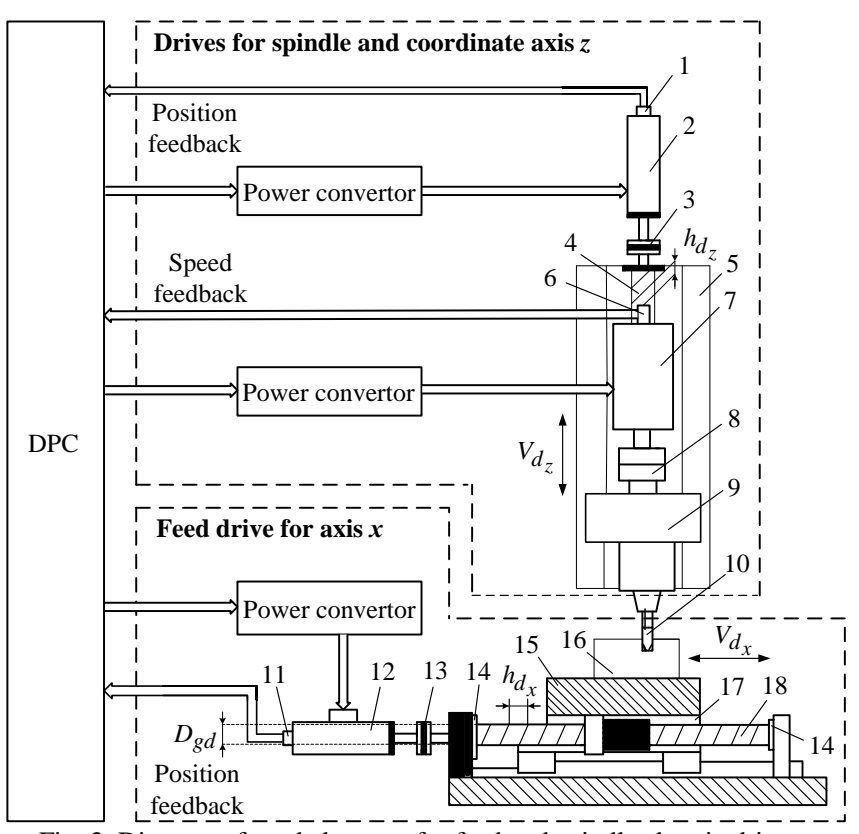

Fig. 3. Diagram of used elements for feed and spindle electric drives.

Fig. 3 shows a diagram, illustrating the used elements for feed and spindle electric drives. The notations used are as follows: DPC - digital program control device; 1 - position sensor for $z$ axis; 2 - motor for $z$ axis; 3 - coupling between the motor and the ball screw for $z$ axis; 4 - ball screw for $z$ axis; 5 - guides for $z$ axis; 6 - speed sensor for spindle drive; 7 - spindle motor; 8 - coupling between the spindle motor and gearbox; 9 - gearbox for spindle drive; $10-$ drilling instrument; 11 - position sensor for $x$ axis; 12 motor for $x$ axis; 13 - coupling between the motor and the ball screw for $x$ axis; 14 - precision bearings for $x$ axis; 15 driven mechanism (work desk for the workpiece); 16 processed workpiece; 17 - guides for $x$ axis; 18 - ball screw for $x$ axis; $h_{d_{x}}$ and $h_{d_{z}}$ - nominal steps of the ball screw for 
$x$ and $z$ axes; $D_{g d_{x}}$ - nominal diameter of the mechanical gear made by a ball screw for $x$ axis; $V_{d_{x}}$ and $V_{d_{z}}$ - speeds of the $x$ and $z$ axes.

Some examples of using this methodology for selection of electric drive systems for cutting materials with different hardness are presented below.

\section{TABLE I: RESULTS FROM THE CALCULATIONS}

\begin{tabular}{|c|c|c|c|}
\hline Step & Operation & Unalloyed steel & Aluminium alloys \\
\hline 1. & $\begin{array}{l}\text { Determination } \\
\text { of } H_{B} \text {. }\end{array}$ & 150 & 60 \\
\hline 2. & $\begin{array}{l}\text { Drilling operation } \\
\text { choice. }\end{array}$ & $\begin{array}{l}\text { Average diameter } \\
\text { of holes }\end{array}$ & $\begin{array}{l}\text { Average diameter } \\
\text { of holes }\end{array}$ \\
\hline 3. & Tool selection. & CoroDrill 880 & CoroDrill 880 \\
\hline 4. & $\begin{array}{l}\text { Determination } \\
\text { of } V_{c d} \text {. }\end{array}$ & $\approx 3.17 \mathrm{~m} / \mathrm{s}$ & $\approx 5 \mathrm{~m} / \mathrm{s}$ \\
\hline 5. & $\begin{array}{l}\text { Determination } \\
\text { of } f_{r d} \text {. }\end{array}$ & $1.75 \times 10^{-5} \mathrm{~m} / \mathrm{rad}$ & $2.2 \times 10^{-5} \mathrm{~m} / \mathrm{rad}$ \\
\hline 6. & $\begin{array}{l}\text { Determination } \\
\text { of } f_{z d} \text {. }\end{array}$ & $0.4 \times 10^{-3} \mathrm{~m} / \mathrm{z}$ & $0.4 \times 10^{-3} \mathrm{~m} / \mathrm{z}$ \\
\hline 7. & $\begin{array}{l}\text { Determination } \\
\text { of } K_{c f z d} \text {. }\end{array}$ & $2100 \mathrm{MPa}$ & $500 \mathrm{MPa}$ \\
\hline 8. & Calculation of $\omega_{d}$. & $\approx 211.33 \mathrm{rad} / \mathrm{s}$ & $\approx 333.33 \mathrm{rad} / \mathrm{s}$ \\
\hline 9. & Calculation of $V_{f d}$. & $\approx 3.7 \times 10^{-3} \mathrm{~m} / \mathrm{s}$ & $\approx 7.33 \times 10^{-3} \mathrm{~m} / \mathrm{s}$ \\
\hline 10. & $\begin{array}{l}\text { Calculation } \\
\text { of } P_{c d \max } \text {. }\end{array}$ & $\approx 6455.3 \mathrm{~W}$ & $\approx 3047.65 \mathrm{~W}$ \\
\hline 11. & Calculation of $P_{c d w}$. & $\approx 7746.4 \mathrm{~W}$ & $\approx 3474.3 \mathrm{~W}$ \\
\hline 12. & Calculation of $P_{s p d}$. & $\approx 7359.1 \mathrm{~W}$ & $\approx 3657.2 \mathrm{~W}$ \\
\hline 13. & Calculation of $P_{f d}$. & $\approx 387.4 \mathrm{~W}$ & $\approx 182.9 \mathrm{~W}$ \\
\hline \multirow{4}{*}{14.} & \multirow{4}{*}{$\begin{array}{l}\text { Determination of } h_{d i} \\
(i=1 \div 4)\end{array}$} & $h_{d 1}=0.005 \mathrm{~m}$ & $h_{d 1}=0.005 \mathrm{~m}$ \\
\hline & & $h_{d 2}=0.01 \mathrm{~m}$ & $h_{d 2}=0.01 \mathrm{~m}$ \\
\hline & & $h_{d 3}=0.02 \mathrm{~m}$ & $h_{d 3}=0.02 \mathrm{~m}$ \\
\hline & & $h_{d 4}=0.04 \mathrm{~m}$ & $h_{d 4}=0.04 \mathrm{~m}$ \\
\hline \multirow{4}{*}{15.} & \multirow{4}{*}{$\begin{array}{l}\text { Calculation of } \omega_{f d_{i}} \\
(i=1 \div 4)\end{array}$} & $\omega_{f d_{1}} \approx 628 \mathrm{rad} / \mathrm{s}$ & $\omega_{f d_{1}} \approx 628 \mathrm{rad} / \mathrm{s}$ \\
\hline & & $\omega_{f_{d 2}} \approx 314 \mathrm{rad} / \mathrm{s}$ & $\omega_{f_{d 2}} \approx 314 \mathrm{rad} / \mathrm{s}$ \\
\hline & & $\omega_{f_{d 3}} \approx 157 \mathrm{rad} / \mathrm{s}$ & $\omega_{f_{d 3}} \approx 157 \mathrm{rad} / \mathrm{s}$ \\
\hline & & $\omega_{f_{d 4}} \approx 78.5 \mathrm{rad} / \mathrm{s}$ & $\omega_{f_{d 4}} \approx 78.5 \mathrm{rad} / \mathrm{s}$ \\
\hline \multirow{4}{*}{16.} & \multirow{4}{*}{$\begin{array}{l}\text { Calculation of } M_{f d_{i}} \\
(i=1 \div 4)\end{array}$} & $M_{f d_{1}} \approx 0.6 \mathrm{Nm}$ & $M_{f d_{1}} \approx 0.3 \mathrm{Nm}$ \\
\hline & & $M_{f d 2} \approx 1.2 \mathrm{Nm}$ & $M_{f d 2} \approx 0.6 \mathrm{Nm}$ \\
\hline & & $M_{f d 3} \approx 2.5 \mathrm{Nm}$ & $M_{f d 3} \approx 1.2 \mathrm{Nm}$ \\
\hline & & $M_{f d 4} \approx 4.9 \mathrm{Nm}$ & $M_{f d 4} \approx 2.3 \mathrm{Nm}$ \\
\hline
\end{tabular}

The input data are as follows: the heaviest cutting regime of operation - at unalloyed steel and aluminium alloys; $D_{c d \text { max }}=0.03 \mathrm{~m} ; \quad D_{g d}=0.04 \mathrm{~m} ; \quad \eta_{d}=0.85$, $V_{d \text { max }} \approx 0.5 \mathrm{~m} / \mathrm{s}$, mechanical gear ratio for spindle: $K_{\text {spd }}=1$. The results obtained are given in Table I.

The calculations performed according to the presented methodology have the same input data for materials of different hardness, in order to compare and analyze the obtained results. The required nominal values of the motor torque for feed drives and of motor power for the spindle drive are determined as follows:

- for machining of unalloyed steel:

$$
\begin{aligned}
& \left\{\begin{array}{l}
M_{f d_{1 \mathrm{nom}}} \approx 1.1 \times M_{f d_{1}} \approx 0.66 \mathrm{Nm} ; \\
M_{f d_{2 \mathrm{nom}}} \approx 1.1 \times M_{f d_{2}} \approx 1.32 \mathrm{Nm} ; \\
M_{f d_{3 \mathrm{nom}}} \approx 1.1 \times M_{f d_{3}} \approx 2.75 \mathrm{Nm} ; \\
M_{f d_{4 \mathrm{nom}}} \approx 1.1 \times M_{f d_{4}} \approx 5.39 \mathrm{Nm} .
\end{array}\right. \\
& P_{\text {spdnom }} \approx 1.1 \times P_{s p d} \approx 8095 \mathrm{~W} .
\end{aligned}
$$

- for machining of aluminium alloys:

$$
\begin{aligned}
& \left\{\begin{array}{l}
M_{f d_{1 \mathrm{nom}}} \approx 1.1 \times M_{f d_{1}} \approx 0.33 \mathrm{Nm} ; \\
M_{f d_{2 \mathrm{nom}}} \approx 1.1 \times M_{f d_{2}} \approx 0.66 \mathrm{Nm} ; \\
M_{f d_{3 \mathrm{nom}}} \approx 1.1 \times M_{f d_{3}} \approx 1.32 \mathrm{Nm} ; \\
M_{f d_{4 \mathrm{nom}}} \approx 1.1 \times M_{f d_{4}} \approx 2.53 \mathrm{Nm} .
\end{array}\right. \\
& P_{\text {spdnom }} \approx 1.1 \times P_{s p d} \approx 3821.73 \mathrm{~W} .
\end{aligned}
$$

The selected motors must have nominal torques and power of about $10 \%$ greater than the calculated ones, in order to compensate for the allowable wear over time. These obtained values are used for the motor choice from the respective technical catalogues.

\section{TABLE II: BASIC DATA OF THE SELECTED ELECTRIC DRIVES}

In machining of unalloyed steel, DC feed and spindle electric drives with the following parameters are selected [15]-[17]:

- ball screw with diameter $0.04 \mathrm{~m}$ and step $h=0.02 \mathrm{~m}$;

- DC motor 3PI12.09 for feed drive with nominal data:

$M_{f d \mathrm{nom}}=3.5 \mathrm{Nm}, \omega_{f d \mathrm{nom}}=209.34 \mathrm{rad} / \mathrm{s}$;

- position sensor for feed drive: encoder model $7 \mathrm{~L}$ with resolution 2500 pulses/rev.;

- power converter for feed drive SA-12;

- DC spindle motor MP112MA with nominal data: $P_{s p d n o m}=13 \mathrm{~kW}$,

$\omega_{s p d \text { nom }}=238.6 \mathrm{rad} / \mathrm{s}, V_{s p d \text { nom }}=400 \mathrm{~V}, I_{s p d a}=38 \mathrm{~A}$;

- thyristor converter $8 \mathrm{EOA}$ for spindle drive.

In machining of aluminium alloys, AC feed and spindle electric drives with the following parameters are selected [15], [18]-[20]:

- ball screw with diameter $0.04 \mathrm{~m}$ and step $h=0.01 \mathrm{~m}$;

- AC motor DT5-3-10 for feed drive with nominal data:

$M_{f d \text { nom }}=1.2 \mathrm{Nm}, \omega_{f d \text { nom }}=439.6 \mathrm{rad} / \mathrm{s}$ with resolver for feedback; - power converter KW2 for feed drive;

- AC spindle motor DH 10-40 with nominal data: $V_{s p d \text { nom }}=350 \mathrm{~V}$,

$I_{s p d \mathrm{nom}}=15 \mathrm{~A}$;

- power converter for spindle drive KW8.

As a result of the calculations made for these two materials, appropriate DC and AC electric drives were chosen. Some of their basic parameters are presented in Table II.

\section{PRACTICAL APPLICATION}

The practical application of a modernized drilling machine is illustrated by the implemented DC feed and spindle electric drives and the respective mechanical process.

Detailed testing has been carried out by means of computer simulation and experimental research for different controllers' tunings and operating regimes. 
Experimentally obtained oscillograms are presented in Fig. 4. Fig. 4a shows speed trajectories along the $x, y$ and $z$ axes. The selected mechanical gears are of ball-screw type with the following coefficients:

$K_{g x}=K_{g y}=K_{g z}=10 \mathrm{~mm} / \mathrm{rev} \approx 1.6 \times 10^{-3} \mathrm{~m} / \mathrm{rad}$.

An oscillogram for the spindle drive with reference speed $157 \mathrm{rad} / \mathrm{s}$ is presented in Fig. 4b.

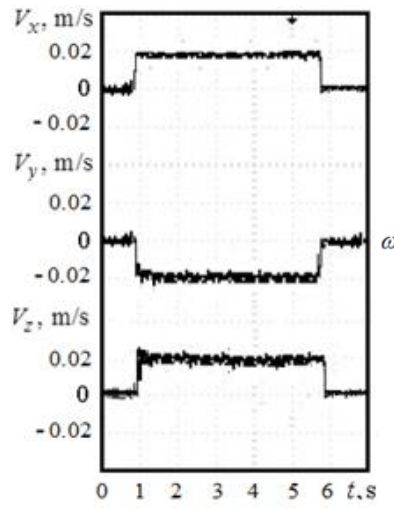

a)

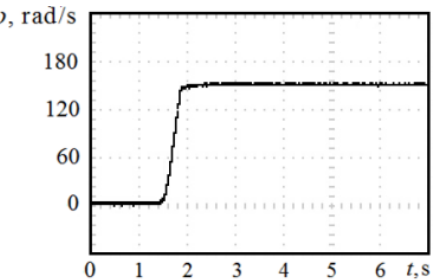

b)
Fig. 4. Speed oscillograms of the DC feed and spindle drive.

Fig. 5 shows an oscillogram illustrating the performance of the $x$ axis drive for one position cycle.

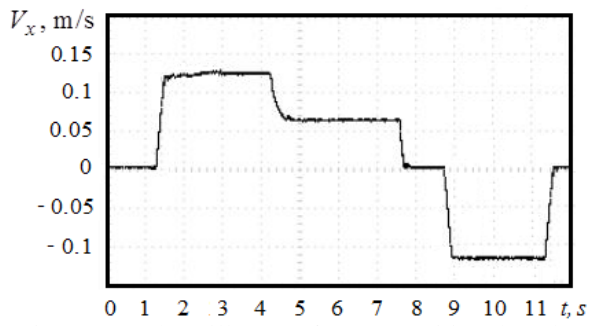

Fig. 5. Speed oscillogram for one positional cycle.

Fig. 6 presents the drilling process with tool diameter of $0.025 \mathrm{~m}$.

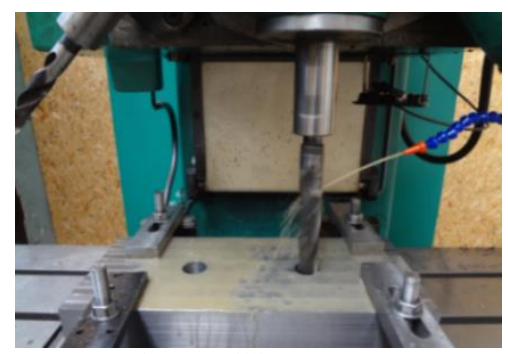

Fig. 6. Drilling process.

\section{CONCLUSION}

The basic requirements for the drive system of a class of modernized drilling machines with digital program control are analyzed and formulated. On this basis, a methodology for optimal choice of feed and spindle drives is offered.

The presented algorithm takes into account the specific features of the technological processes, the processed materials, the tools used, and the mechanical gear types.

Examples for selection of feed and spindle drives with DC and AC motors are presented, illustrating the practical application of this methodology.

The research held and the results obtained can be used in the development of drive systems for the studied class of machine tools.

\section{ACKNOWLEDGMENT}

This work is supported by the Technical University of Sofia, Bulgaria under Research Project No. 181PR0003-08 /2018.

\section{REFERENCES}

[1] Popov G., Machine tools, part I: Applicability, device and control, Second book, Technical of University of Sofia, Sofia, 2010, ISBN 978-954-438-766-2.

[2] Tata McGraw-Hill Education, Manufacturing Technology: Metal cutting and machine tools, Vol. 2, 2013, ISBN 9781259029561.

[3] Youssef, H. A., H. El-Hofy, Machining Technology: Machine Tools and Operations, CRC Press, 2008, ISBN 9781420043402.

[4] Mikhov M., M. Zhilevski, Analysis of a Multi-Coordinate Drive System Aiming at Performance Improvement, Proceedings of the International Conference "Research and Development in Mechanical Industry", Vol. 2, pp. 1102-1107, Vrnjacka Banja, Serbia, 2012, ISBN 978-86-6075-037-4.

[5] Mikhov M., M. Zhilevski, Performance Improvement of a Type of Milling Machines, Proceedings of the International Conference "Research and Development in Mechanical Industry", Vol. 1, pp. 218-227, Kopaonik, Serbia, 2013, ISBN 978-86-6075-042-8.

[6] Altintas, Y., A. Verl, C. Brecher, L. Uriarte, G. Pritschow, Machine Tool Feed Drives, CIRP Annals - Manufacturing Technology, vol. 60, No. 2, pp. 779 -796, 2011, ISSN: 0007-8506.

[7] Mikhov M., Electric Drive Systems, Technical University of Sofia, Sofia, 2011, ISBN 978-954-438-922-2.

[8] Bose B. K., Power electronics and motor drives: advances and trends. London, Academic Press, 2006, ISBN 978-0-12-088405-6.

[9] DIN 69051-3: Werkzeugmaschinen; Kugelgewindetriebe; Abnahmebedingungen und Abnahmeprüfungen, 1998.

[10] DIN 69051-4: Kugelgewindetriebe-Berechnung der statischen und dynamischen Tragzahl sowie der Lebensdauer, Entwurf April 1989.

[11] Sandvik Coromant, Metalcutting Technical Guide: Turning, Milling, Drilling, Boring, Toolholding, Sandvik, 2005.

[12] Sandvik Coromant, Tool Selection Guide, Selected Assortment in Turning-Milling-Drilling, Sandvik, 1997.

[13] Andonov I., Cutting of Metals, Softtrade, Sofia, 2001 (In Bulgarian).

[14] Braitinger, H., Elektrische Antriebstechnik, AMK Arnold Müller, 2004.

[15] Precision Ball Screw Assemblies, Rexroth Bosch Group, Catalogue, 2009.

[16] SERVOMOTORS, Gama Motors Catalogue, 2014.

[17] http://www.zgpu-group.com/archives/category/sensors.

[18] AMKASYN, Servo Drives KE/KW, AMK Catalogue, 2014.

[19] DYNASYN, Servo Motors DT and DP, AMK Catalogue, 2014.

[20] AMKASYN, AC Servo- and Main Spindle Motors, AMK Catalogue, 2014.
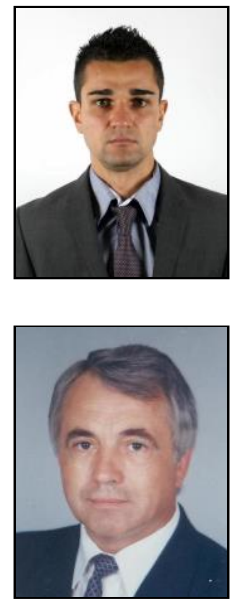

Marin M. Zhilevski was born in 1986 in Gabrovo, Bulgaria. $\mathrm{He}$ is an Assistant Professor at the Technical of University of Sofia, Faculty of Automatics, Department of Electrical Motion Automation Systems. He received his $\mathrm{PhD}$ in Electric Drives in 2015. His interests are related to Control of Electric Drive Systems, Machine Tools, Programmable Logic Devices and Systems, Automatics, Robotics, etc.

Mikho R. Mikhov was born in 1948. He received his MSc degree in Electrical Engineering in 1972 and his PhD in Industry Automation in 1983 from the Technical University of Sofia, Bulgaria. $\mathrm{He}$ is Professor at the Faculty of Automatics, Technical University of Sofia. He is interested in Electric Drives, Control of Electromecanical Systems, Industry Automation, Wireless Monitoring and Control, and Computer Simulation. 